\title{
Configurações da Política de Assistência da União para a Oferta da Educação Básica Pós-Golpe de 2016
}

\author{
Cacilda Rodrigues Cavalcanti \\ Universidade Federal do Maranhão (UFMA), São Luís/MA - Brasil
}

\section{Resumo}

O artigo analisa a política de assistência técnica e financeira da União aos entes federados subnacionais pós-golpe de 2016, a partir de dados quantitativos de transferências de recursos do FNDE para os governos estaduais, distrital e municipais. Os dados apontam que os novos rumos do governo federal afetaram negativamente as ações de assistência da União, incidindo na diminuição do montante de recursos, na priorização da reforma do ensino médio e na barganha político-partidária entre legislativo e executivo.

Palavras-chave: Financiamento da Educação. Assistência da União. Federalismo.

\section{Union Assistance Policy Settings for K-12 Education Offering}

\section{Following the 2016 Coup}

\section{Abstract}

The paper analyzes the Union's technical and financial assistance policy to sub-national governments, after the coup d'etat of 2016, based on quantitative data of transfer of resources from FNDE to state, district and municipal governments. The data indicate that the new direction of the federal government has adversely affected the Union's assistance actions, reducing the amount of resources, prioritizing high school reform and political-partisan bargaining between legislative and executive.

Keywords: Financing of Education. Union Assistance. Federalism. 
Configurações da Política de Assistência da União para a Oferta da Educação Básica Pós-Golpe de 2016

\section{Introdução'}

A legislação educacional brasileira (Lei n 9.394/1996 e Lei n 11.494/2007) estabelece a obrigatoriedade da União de prestar assistência técnica e financeira aos estados, ao Distrito Federal e aos municípios para a oferta de educação básica, como parte de sua função supletiva e redistributiva, tendo como referência os princípios de equidade e qualidade.

A ação de assistência técnica e financeira da União aos entes federados subnacionais encontra ampla referência na literatura do federalismo. Autores como Oates (1968), Watts (2008) e Arretche (2012) defendem que, em países marcados por grandes desigualdades regionais, como é o caso brasileiro, torna-se necessário que o governo central concentre a arrecadação de impostos de base ampla (a exemplo do imposto sobre renda) e que exerça a função redistributiva e supletiva em relação aos governos subnacionais, a fim de amenizar as assimetrias entre os diversos entes da federação na oferta dos serviços públicos.

Assim, a assistência técnica e financeira da União está fundamentada, por um lado, no princípio do direito de todos aos bens públicos fundamentais, a exemplo da saúde, educação, assistência social, independentemente do local de moradia dos cidadãos, cuja proteção é prerrogativa do Estado-nação e, por outro, no princípio da equidade horizontal e vertical entre os entes da federação, ou seja, que o direito seja efetivado na perspectiva da correção das desigualdades, o que evoca também o princípio da justiça social. Sendo essa uma das principais formas de a União exercer sua função supletiva e redistributiva em matéria educacional, objetiva tanto uma perspectiva de suplementar quanto de redistribuir os recursos financeiros da educação entre os entes subnacionais. Tais premissas conduziram, ao longo das duas últimas décadas, a um conjunto de debates e iniciativas da sociedade civil e dos governos na direção de uma ação mais proeminente do governo federal no exercício de sua função supletiva e redistributiva, resultando em uma política de assistência técnica e financeira que combinou maior aporte de recursos federais, mecanismos de indução da agenda dos governos subnacionais, maior diversificação de programas e ações focadas nos municípios com menores indicadores educacionais. Essa política teve sua estruturação final no Plano de Desenvolvimento da Educação, que combinou dois mecanismos complementares: um de avaliação (Índice de Desenvolvimento da Educação Básica - IDEB) e outro de planejamento (Plano de Ações Articuladas - PAR).

Com o Golpe de Estado de $2016^{2}$, o corte de gastos com as políticas sociais voltou a ganhar espaço na agenda do governo federal, tendo como sua expressão máxima e imediata a Emenda Constitucional $n^{\circ}$ 95, de 15 de dezembro de 2016, que instituiu um novo Regime Fiscal no âmbito dos Orçamentos Fiscal e da Seguridade Social da União, que vigorará por vinte exercícios financeiros (20 anos), nos termos dos artigos 106 a 114 do ADCT. Essa medida, articulada a um conjunto de proposições de reformas, como a reforma trabalhista, a

\footnotetext{
Apoio: Fundação de Amparo à Pesquisa e ao Desenvolvimento Científico e Tecnológico do Maranhão.

2 Golpe de Estado aqui é compreendido a partir da acepção de Bianchi (2016, p. 6): "O golpe de estado não é um golpe no Estado ou contra o Estado. Seu protagonista se encontra no interior do próprio Estado, podendo ser, inclusive, o próprio governante. Os meios são excepcionais, ou seja, não são característicos do funcionamento regular das instituições políticas. Tais meios se caracterizam pela excepcionalidade dos procedimentos e dos recursos mobilizados. O fim é a mudança institucional, uma alteração radical na distribuição de poder entre as instituições políticas, podendo ou não haver a troca dos governantes".
} 
Configurações da Política de Assistência da União para a Oferta da Educação Básica Pós-Golpe de 2016

reforma da previdência e a reforma do ensino médio, implica diretamente no investimento em educação e nas possibilidades de alcance das metas do Plano Nacional de Educação (PNE).

Este artigo propõe uma análise, ainda incipiente, sobre as novas configurações que a política de assistência técnica e financeira da União assumiu a partir de 2016, em especial no que se refere às transferências voluntárias, para os governos subnacionais, visando a oferta de educação básica. Para tanto, o artigo inicia com uma revisão da política de assistência técnica e financeira do governo federal durante o governo do Partido dos Trabalhadores (PT), para depois identificar as mudanças que foram realizadas no governo Temer.

\section{A Política de Assistência Técnica e Financeira da União Durante o Governo do PT}

A Constituição Federal de 1988 , no $\S 1^{\circ}$, do seu artigo 211 , determina que a União deve exercer, "[...] em matéria educacional, função redistributiva e supletiva, de forma a garantir equalização de oportunidades educacionais e padrão mínimo de qualidade do ensino mediante assistência técnica e financeira aos Estados, ao Distrito Federal e aos Municípios".

Atualmente, a assistência técnica e financeira da União para a Educação básica tem como principais mecanismos: a complementação ao Fundeb, os programas de assistência técnica e financeira legais e voluntários. Os programas compreendem as transferências legais, feitas por meio do Programa Nacional de Alimentação Escolar (PNAE), Programa Nacional de Apoio a Transporte do Escolar (PNATE), o Programa Dinheiro Direto na Escola (PDDE) e o Programa de Apoio aos Sistemas de Ensino para Atendimento à Educação de Jovens e Adultos, além de os programas de transferências voluntárias, que compreendiam, até 2014 , um total de 37 programas, sob os quais o governo federal possui discricionariedade.

De um modo geral, a assistência financeira da União para a educação básica é tratada no Manual de Assistência Financeira do Fundo Nacional de Desenvolvimento da Educação, que estabelece critérios e condições para a sua execução, aprovado por resoluções específicas do Conselho Deliberativo do Fundo Nacional de Desenvolvimento da Educação (FNDE). Porém, em consonância com o manual em vigência em cada período, as resoluções que regulamentam as transferências estabelecem as especificidades para cada programa ou ação.

Ao realizar sua função de assistência técnica e financeira, a União não apenas transfere recursos financeiros para os demais entes, mas também regulamenta seus fins, sua forma e seus procedimentos, configurando modelos de políticas a serem implementados pelos estados e municípios. A partir desse pressuposto, nesta seção analisa-se a política de assistência da União aos entes federados subnacionais para a oferta da educação básica durante o governo do Partido dos Trabalhadores (PT), tendo, portanto, como recorte temporal o período de 2003 a 2014, correspondendo aos dois mandatos do Presidente Lula e um mandato da Presidenta Dilma.

Um novo modelo de assistência da União aos entes federados subnacionais para a oferta de educação básica vai ganhando forma a partir de 2004, já que, em 2003, ainda se está sob a égide do orçamento plurianual do governo anterior. Até o ano de 2003, existiam no FNDE 24 programas destinados a prestar assistência aos governos subnacionais, sendo cinco deles programas legais. Assim, tal assistência se dava, principalmente, por meio de Planos de Trabalho Anual (PTAs), elaborados pelos entes subnacionais para solicitar ajuda técnica e financeira da União, em respostas a editais lançados pelo Ministério da Educação (MEC). No 
Configurações da Política de Assistência da União para a Oferta da Educação Básica Pós-Golpe de 2016

Manual de Assistência Financeira de 2003, o governo federal já indicava que mudanças seriam feitas na política de assistência técnica e financeira da União aos governos subnacionais.

Apesar das limitações impostas, tanto pelo PPA quanto pelo Orçamento da União, o Ministério da Educação começa a apontar as mudanças que devem ser feitas na política educacional, tendo como referência os programas e ações a serem apoiados financeiramente com recursos do FNDE, em 2003.

$[\ldots]$

As bases atuais de financiamento da educação estão sendo rediscutidas pelo atual governo. É preciso garantir financiamento adequado não só ao ensino fundamental, mas a toda a educação básica (BRASIL, 2003).

A partir de 2004, novos programas são criados e antigos começam a ser reconfigurados, chegando a um total de 43 programas em 2014. Nesse movimento, a demanda de assistência por meio de PTAs vai, gradativamente, sendo extinta e os programas passam a ter suas ações e forma de execução cada vez mais detalhadas. Grupos de municípios beneficiários passam a ser previamente selecionados pelo MEC/FNDE.

O novo desenho da assistência da União teve seu ponto máximo em 2007, com a implantação do Plano de Desenvolvimento da Educação (PDE), que reestruturou todos os programas de assistência da União sob uma única política, articulando avaliação e planejamento dos sistemas estaduais e municipais de educação. O PDE tem como mecanismos básicos o Índice de Desenvolvimento da Educação Básica (IDEB) e o Plano de Ações Articuladas (PAR). O IDEB foi criado pelo Ministério da Educação para medir o nível de desenvolvimento da educação básica de cada estado e cada município brasileiro. A partir desse indicador, o MEC estabeleceu metas a serem alcançadas pelos entes subnacionais, propôs a elaboração do PAR como forma de alcançar as metas propostas e condicionou sua assistência à elaboração de tal plano e ao alcance das metas. Inicialmente, foram priorizados, para receber assistência da União, 1.242 municípios com o IDEB mais baixo, conforme explicita a citação seguinte do livro de orientações do PDE.

O IDEB permite identificar as redes e as escolas públicas mais frágeis a partir de critérios objetivos e obriga a União a dar respostas imediatas para os casos mais dramáticos ao organizar o repasse de transferências voluntárias com base em critérios substantivos, em substituição ao repasse com base em critérios subjetivos. $O$ escopo é atender imediatamente os 1.242 municípios e as 7.085 escolas com os mais baixos indicadores e, em curto prazo, todos os que estejam abaixo da média nacional. Isso exigirá do Ministério da Educação uma mudança de postura radical no atendimento aos entes federados. Em vez de aguardar as respostas às suas resoluções, selecionando os 'melhores' projetos apresentados, muitas vezes elaborados por consultorias contratadas, trata-se de ir ao encontro de quem mais precisa, construindo o regime de colaboração na prática. O Ministério da Educação precisa sair de Brasília e conhecer seus parceiros. Só assim o relacionamento entre governos, mediado pelo tráfico de influência, pela pressão político-partidária ou pelo jogo de interesses, dará lugar ao relacionamento entre Estado nacional e os entes federados, mediado pelo direito de aprender do educando (BRASIL, 2007b, p. 23).

Com a nova política, ocorreu também uma redefinição de parâmetros para calcular o valor per capita a ser transferido nos diversos programas, os quais passaram a ser diferenciados considerando a diversidade de condições de oferta educacional no país região, localização (rural ou urbana), etapa e modalidades de ensino, situação econômica do 
ente federado, entre outros. A nova política de assistência da União teve como princípio basilar a garantia da equidade entre os entes federados, portanto, visava priorizar estados e municípios em condições de oferta da educação mais desaforáveis, cuja maioria se encontrava nas regiões Norte e Nordeste do País.

O novo desenho das políticas de assistência técnica e financeira da União incorporou um conjunto de medidas estratégicas que possibilitaram maior poder de influência da agenda educacional dos governos subnacionais, tais como: a) a organização da assistência técnica e financeira, preferencialmente por meio de programas formatados nacionalmente, mas incorporando, ao mesmo tempo, componentes de diversidade; b) regulamentação da assistência técnica e financeira para além de seus aspectos técnico-burocráticos, incorporando princípios e arranjos político-pedagógicos, de forma que os programas passaram a se constituir em mais do que veículos de transferência de recursos, mas também mecanismos de introdução de políticas de educação básica elaborados pelo governo federal nos sistemas estaduais e municipais de educação; c) orientação do planejamento geral dos sistemas subnacionais de educação por meio do PAR, vinculando o recebimento de recursos da assistência técnica e financeira voluntária do MEC à elaboração do PAR e ao alcance das metas do IDEB, por meio de assinatura do Termo de Compromisso Todos pela Educação; e d) priorização de grupos de municípios como beneficiários de determinadas políticas elaboradas pelo MEC, conforme seus indicadores educacionais.

Esses mecanismos aumentaram a capacidade de coordenação federal no campo da educação básica por conta, principalmente, de suas complementaridades, de forma que cada mecanismo incide sobre determinados aspectos da agenda educacional e das relações federativas, indo do nível mais macro (do planejamento da política municipal/estadual de educação) ao nível mais micro (do formato das ações a serem implementadas pelas escolas).

Em segundo lugar, o governo aumentou também seu poder de influência sobre a agenda educacional dos governos subnacionais, mobilizando recursos e construindo mecanismos para controlar as instâncias de negociação e de mediação de suas políticas de assistência financeira. A regulamentação da assistência da União por meio de resoluções do executivo federal constituiu mecanismo eficaz de implementação de políticas educacionais, entre outras razões, porque coibiram veto players ${ }^{3}$ próprios do regime federativo. Observouse que o governo federal, por meio de cada política específica, passou a controlar as arenas de negociações. Um desses mecanismos foi a regulamentação das transferências legais e voluntárias pelo FNDE, autarquia do MEC responsável pelas transferências dos recursos financeiros da União a título de assistência financeira, sem a participação efetiva dos demais entes federados, indicando uma definição unilateral, pela União, dos critérios e procedimentos de tais transferências, já que não há no interior do FNDE nenhuma instância de coordenação federativa. Isso implicou em um deslocamento da arena principal de formulação das políticas educativas (o parlamento e o Ministério da Educação) para uma arena mais insulada ao controle social e a veto players. Assim, o FNDE se consolidou como órgão formulador da política nacional de educação no "varejo", uma vez que a regulamentação das transferências

3 Um veto player é um ator individual ou coletivo, institucionais ou partidários cuja concordância é necessária para que se tome uma decisão política. Esse termo vem da teoria de Tsebelis (1995). Cabe ressaltar que aqui usamos apenas a ideia geral da teoria de Tsebelis quanto a recursos políticos, pois sua teoria é voltada para sistemas governamentais, em especial no que se refere à relação entre executivo e legislativo. 
Configurações da Política de Assistência da União para a Oferta da Educação Básica Pós-Golpe de 2016

introduziu princípios, regras, modelos, lógicas de ação e estabeleceu prioridades, delineando uma política educacional de âmbito nacional.

Dados de pesquisa documental de Cavalcanti (2016) evidenciam que o MEC aumentou seu poder de indução da agenda educacional dos governos subnacionais também pela mobilização de recursos políticos para a obtenção do consenso de atores-chave, como a União Nacional dos Dirigentes Municipais de Educação (UNDIME) e a União Nacional dos Conselhos Municipais de Educação (UNCME). O consenso foi obtido tanto pela via de diálogos prévios quanto por meio das transferências de recursos livres de regulamentação para essas entidades, os quais somaram, no período estudado, 27,9 milhões de reais. Tais entidades, como representantes de gestores dos sistemas municipais de educação, têm um grande poder de convencimento e de alinhamento do discurso de suas bases.

Dados de pesquisa quantitativa mostram que o novo desenho da política de assistência da União à educação básica resultou em aumento das transferências de recursos aos entes federados subnacionais.

Em relação ao principal componente da assistência financeira da União - a complementação da União ao Fundo de Manutenção e Desenvolvimento da Educação Básica e Valorização dos Profissionais da Educação (Fundeb), observa-se que as mudanças introduzidas pela Lei $\mathrm{n}^{\circ} 11.494 / 2007$ resultaram em um aumento mais significativo e com efeito mais redistributivo dos recursos transferidos para o referido fundo.

Conforme se pode observar no Gráfico 1, a complementação da União, que vinha em queda desde 1998, passou de um percentual equivalente a $0,7 \%$ do total do Fundo em 2006 (último ano do Fundef) para 10\%, em 2010, conforme o mínimo estabelecido na Lei $\mathrm{n}^{\circ}$ 11.494/2007, que instituiu o Fundeb. Assim, a complementação federal passou, de apenas dois estados contemplados em 2006 (Pará e Maranhão), para dez estados. Além dos já citados, foram incluídos também Alagoas, Bahia, Ceará, Paraíba, Pernambuco, Piauí, Amazonas e Rio Grande do Norte.

Gráfico 1 - Evolução da complementação da União ao Fundef e Fundeb em percentual dos fundos estaduais. Brasil. $1998-2014$

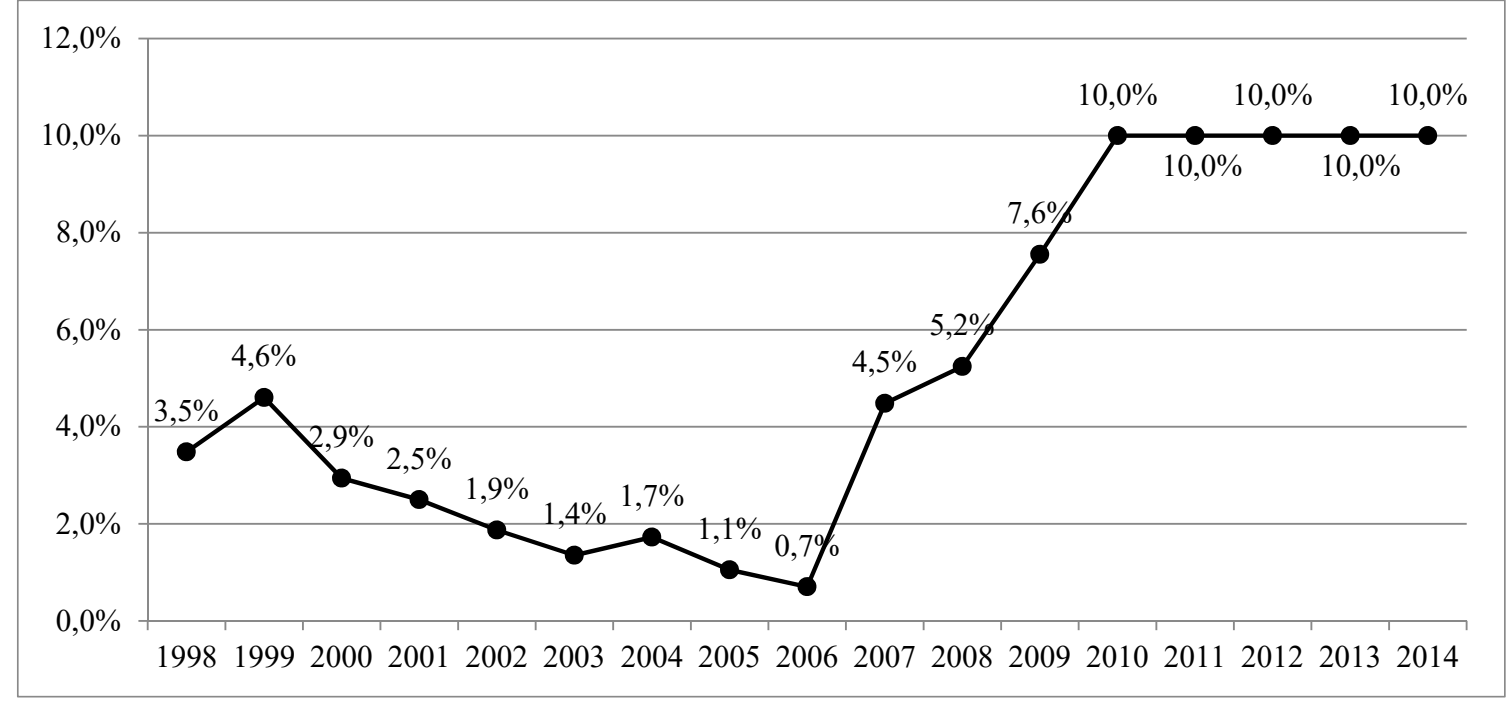

Fonte: Elaboração da autora com base em SIAFI e FNDE.

Nota: Incluem-se no ano anterior os ajustes feitos em abril do ano seguinte, conforme determina a $\mathrm{n}^{\circ} 11.494 / 2007$. 
Configurações da Política de Assistência da União para a Oferta da Educação Básica Pós-Golpe de 2016

Quanto aos recursos oriundos dos programas de assistência da União, também se observou um crescimento significativo, tanto nos programas de assistência legal quanto nos de assistência voluntária, porém, com trajetórias diferentes.

Gráfico 2 - Evolução do valor/aluno dos Programas de Assistência conforme tipo de transferência (Legal e Voluntária). Brasil, 2004 - 2014. Valores reais atualizados pelo IPCA em 09/2015

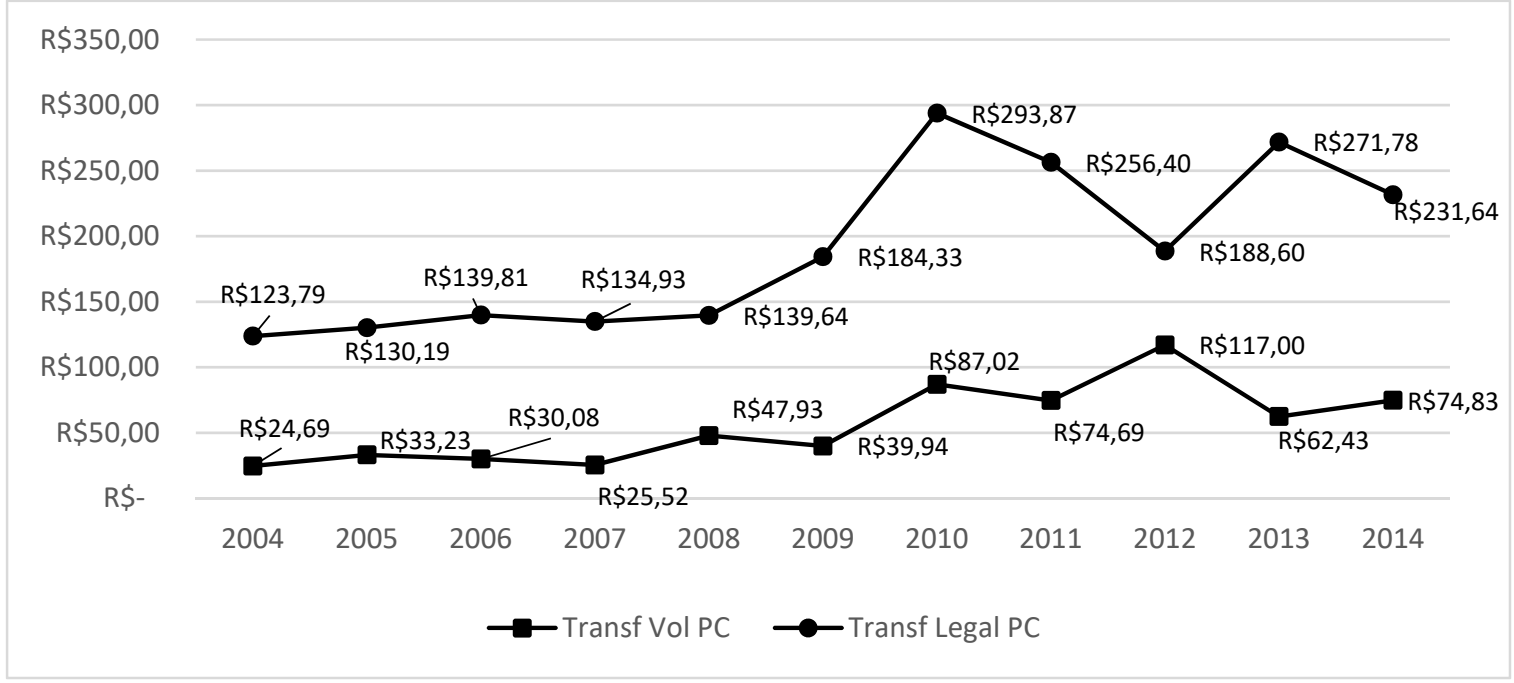

Fonte: Elaboração da autora com base em Portal da Transparência e Censo Escolar (INEP).

As transferências dos Programas de Assistência Legal (PAL) foram mais substantivas que a dos Programas de Assistência Voluntária (PAV), uma vez que os primeiros têm repasses regulares. O valor/aluno passou de $R \$ 123,79$, em 2004 , para $R \$ 293,87$, em 2010 , quando atingiu seu maior valor, apresentando queda a partir de então, mas mantendo ainda um valor significativo em relação ao praticado em 2004. Os PAV, embora tenham operado um valor/aluno menor que os PAL, apresentaram crescimento maior. Considerando o período de maior crescimento - 2004 a 2012 -, o aumento foi na ordem de 303\%.

Assim, pode-se afirmar que a política de assistência técnica e financeira da União ao longo do governo do PT implicou em maior volume de recursos, bem como na diversificação de ações, incorporando um conjunto de políticas de caráter inclusivo, tais como programas voltados para a educação do campo, educação em áreas indígenas e quilombolas, educação especial, relações étnico-raciais. Porém, mesmo com os diversos mecanismos redistributivos adotados para contemplar os municípios em piores condições de oferta da educação, os dados das transferências realizadas mostram que municípios das regiões Sul e Sudeste do País continuaram recebendo mais recursos per capita. Embora tenha ocorrido um acréscimo significativo no valor/aluno transferido para os governos municipais da região Nordeste (923\%), esse aumento foi ainda maior na região Sul (1.196\%).

\section{Mudanças na Configuração da Política de Assistência Técnica e Financeira a partir de 2016}

Logo após o afastamento da Presidenta Dilma Rousseff, em maio de 2016, um conjunto de medidas foram tomadas na direção de ajustar a política educacional ao ideário neoliberal, entre elas a reforma do ensino médio, proposta pela Medida Provisória $n^{\circ} 746 / 2016$, aprovada e transformada na Lei $n^{\circ} 13.415$, de fevereiro de 2017; a PEC 241, que resultou na EC $n^{\circ} 95$, 
que estabeleceu o teto de gastos durante 20 anos; mudanças no processo de aprovação da BNCC; mudanças na composição do Conselho Nacional de Educação e no Fórum Nacional de Educação, ajustando-os aos interesses do setor privado.

No campo específico do financiamento da educação, a Emenda Constitucional $n^{\circ} 95$ tem impactos diretos, uma vez que, durante 20 anos, as despesas primárias do orçamento público ficarão limitadas à variação inflacionária, o que significa que, nesse período, não haverá crescimento real das despesas primárias, implicando na redução dos gastos sociais em porcentagem per capita e em relação ao PIB, o que, por sua vez, afeta ampla e diretamente no alcance da meta 20 do Plano Nacional de Educação, que estabelece investimentos em educação em uma proporção de $10 \%$ do PIB até 2024 . Mariano $(2017$, p. 263) avalia que "com a nova regra, a redução nos gastos com educação seria de $47 \%$ no período", o que garantiria apenas, e de forma muito limitada, a manutenção dos serviços existentes.

As medidas para a redução dos gastos em educação ficam evidentes no documento Um ajuste justo: análise da eficiência e da equidade do gasto público no Brasil, publicado em 2017 pelo Banco Mundial. O documento dedica um capítulo para os gastos em educação, intitulado Gastar mais ou melhor? Eficiência e Equidade da Educação Pública. A partir de uma análise economicista dos gastos com educação pública no Brasil, visando mostrar que o Brasil gasta muito e mal e obtém poucos resultados em educação, o Banco Mundial apresenta suas principais proposições para a redução das despesas públicas com a educação pública, tais como: desvincular o percentual mínimo de $25 \%$ da receita tributária ${ }^{4}$ a ser aplicado em educação; aumentar a razão aluno/professor, que é relativamente baixa; diminuir promoções automáticas e planos previdenciários, que seriam muito generosos; investir em práticas gerenciais; introduzir o pagamento de mensalidades em universidades públicas para as famílias mais ricas e direcionar melhor o acesso ao financiamento estudantil para o ensino superior (programa FIES).

As medidas nessa direção, já em andamento no governo federal, visando a diminuição de gastos do governo federal sob o argumento de recuperação da economia brasileira, tiveram o impacto direto e mais imediato nas ações de assistência técnica e financeira da União para a Educação Básica, conforme pretende-se mostrar a seguir.

O primeiro impacto se refere à complementação da União ao Fundeb, principal mecanismo de financiamento da educação básica, que apresentou queda de valor desde 2016. A União, conforme definido na Lei $n^{\circ} 11.494 / 2007$, deve complementar o Fundeb no valor equivalente a $10 \%$ do total dos fundos, composto pelos $20 \%$ da receita de impostos dos estados e municípios vinculada ao referido fundo. Embora a União venha cumprindo com o percentual estabelecido, o montante de recursos alocados no Fundeb tem sofrido diminuição desde 2016, conforme se pode observar no Gráfico 3. De 2014 para 2015 houve um aumento de $19,98 \%$ no montante de recursos da complementação da União para o Fundeb. Porém, de 2015 para 2016 o aumento foi apenas de 4,9\%; e o valor de 2017 sofreu uma queda de $4,39 \%$ em relação ao ano anterior; ademais, conforme os valores previstos para o ano de 2018 , o montante será menor do que foi em 2017. Desse modo, nos dois últimos anos a quantidade

4 Observa-se um erro de informação no referido documento, ao usar o termo receitas tributárias, uma vez que, conforme a Constituição de 1988, essa vinculação é somente da receita de impostos. 
de estados que receberam complementação diminuiu de 10 estados para apenas nove. Além disso, diminuiu também a quantidade de municípios comtemplados no âmbito de cada estado.

Gráfico 3 - Evolução do montante de recursos da complementação da União ao Fundeb 2014 - 2018

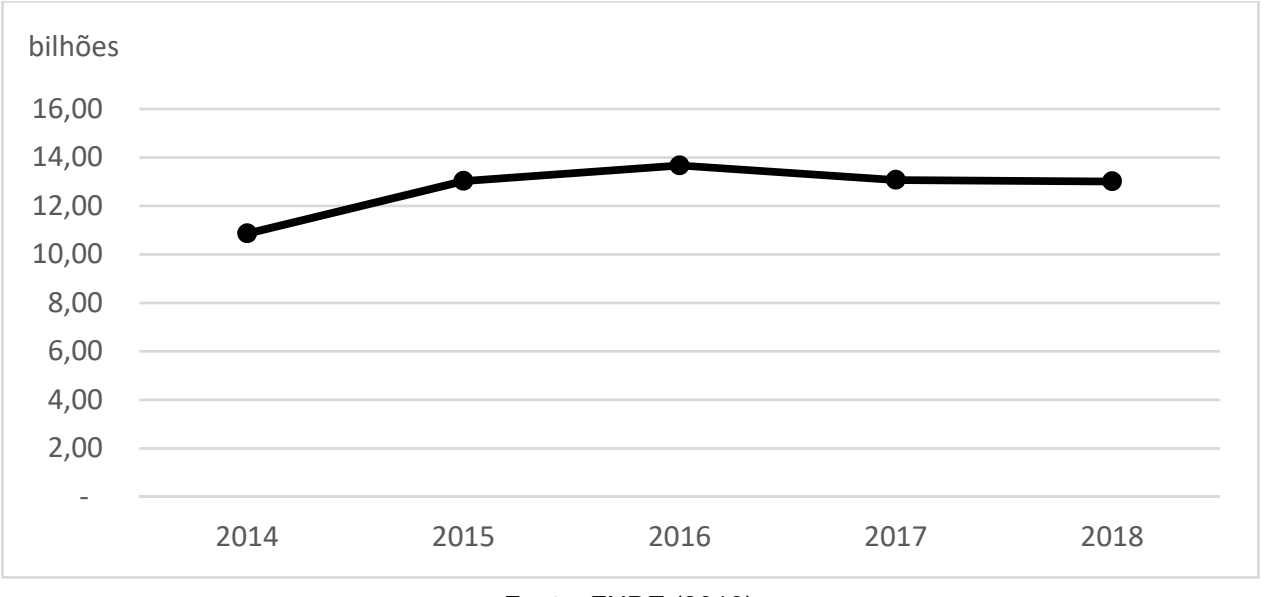

Fonte: FNDE (2018).

Observa-se uma queda no montante de recursos da complementação da União ao Fundeb entre 2016 e 2018. Isso ocorreu, por um lado, porque a União continuou praticando sua complementação com base no percentual mínimo de $10 \%$ do total do Fundo. Assim, considerando que o valor/aluno/ano é calculado a partir do percentual de $20 \%$ dos impostos dos estados e municípios que compõem o Fundo, e que houve diminuição da receita de impostos dos estados e municípios, consequentemente houve diminuição do valor/aluno/ano e na complementação da União. O Gráfico 4 mostra como se comportou o valor/aluno/ano base do Fundeb de 2014 a 2018.

Gráfico 4 - Evolução do valor/aluno/ano base do Fundeb, 2014 - 2018

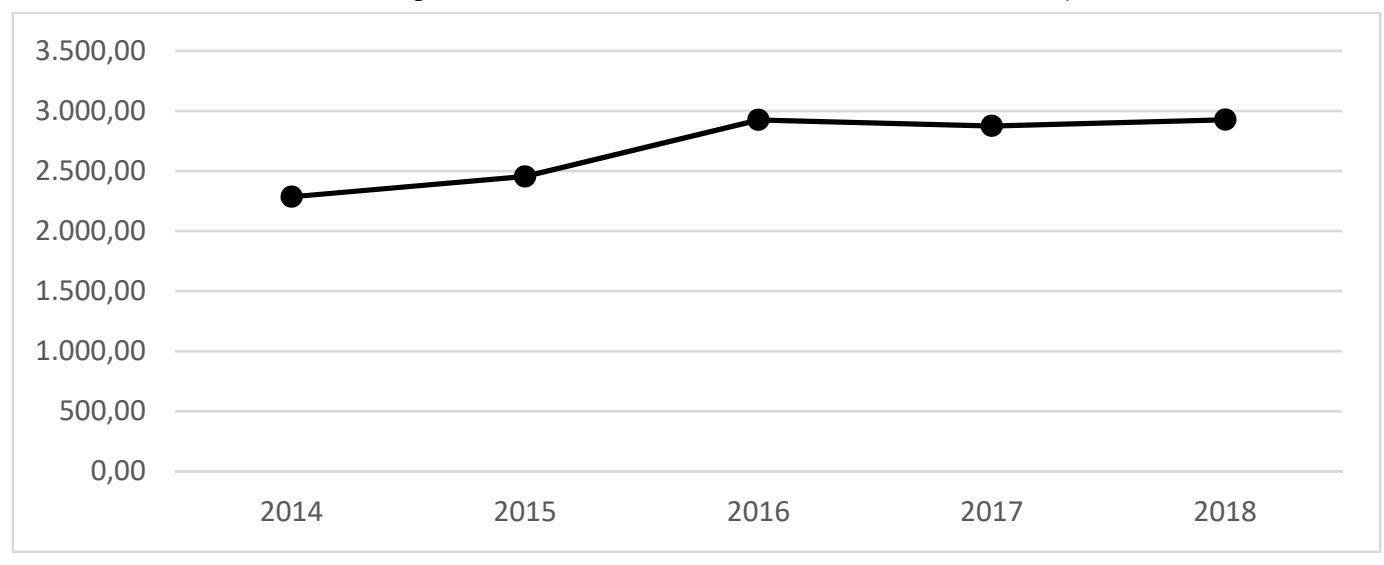

Fonte: FNDE (2018).

O valor/aluno/ano base do Fundeb (séries inicias do ensino fundamental urbano), que, entre 2014 e 2016, teve um aumento de $26,4 \%$, vem apresentando queda na taxa de crescimento desde 2017, afetando, consequentemente, a receita da educação de milhares de municípios, que dependem da complementação da União.

No entanto, são nas ações de assistência técnica e financeira voluntária da União aos entes federados subnacionais, para a oferta de educação básica, que verificamos o maior impacto dos cortes de gastos no governo Michel Temer, tanto no que se refere ao montante de recursos quanto ao tipo de ações priorizadas e ao formato de transferências. 
Configurações da Política de Assistência da União para a Oferta da Educação Básica Pós-Golpe de 2016

Tabela 1 - Recursos da assistência financeira voluntária da União transferidos para os governos estaduais, distrital e municipais - 2014- 2017

\begin{tabular}{|c|c|c|c|c|}
\hline PROGRAMAS & 2014 & 2015 & 2016 & 2017 \\
\hline PROINFÂNCIA & $878.729 .173,62$ & $125.000,00$ & $369.021 .586,45$ & $354.969 .798,52$ \\
\hline BRASIL ALFABETIZADO & $52.777 .675,94$ & $122.798 .968,42$ & 133.126.002,15 & $87.236 .220,00$ \\
\hline PROJOVEM & $141.610 .908,20$ & $163.794 .917,75$ & $50.798 .200,00$ & $8.459 .200,00$ \\
\hline $\begin{array}{l}\text { PROGRAMA DE CONSTRUÇÃO } \\
\text { DE QUADRAS POLIESPORTIVAS }\end{array}$ & 729.979.213,09 & $356.928 .846,97$ & $418.646 .421,62$ & 131.916.172,09 \\
\hline $\begin{array}{l}\text { BRASIL CARINHOSO - } \\
\text { TRANSFERENCIA DIRETA }\end{array}$ & $765.646 .699,04$ & & $545.755 .258,49$ & $39.920 .093,42$ \\
\hline PRONATEC & 2.810.352.224,94 & $1.402 .643 .906,20$ & $1.910 .088 .617,40$ & $286.892 .854,92$ \\
\hline $\begin{array}{l}\text { REESTRUTURAÇÃO DA REDE } \\
\text { FÍSICA PÚBLICA ENSINO } \\
\text { FUNDAMENTAL -CONSTRUCÃO }\end{array}$ & $915.750,00$ & $148.500,00$ & & $349.948,10$ \\
\hline $\begin{array}{l}\text { PROGRAMA DE TRABALHO } \\
\text { ANUAL }\end{array}$ & $326.103 .957,46$ & $115.146 .467,94$ & $316.976 .516,71$ & $92.540 .497,66$ \\
\hline $\begin{array}{l}\text { ÁGUA E ESGOTAMENTO } \\
\text { SANITÁRIO, ESCOLA DO } \\
\text { CAMPO, ESCOLA ACESSÍVEL E } \\
\text { PDE ESCOLA }\end{array}$ & $207.920 .500,00$ & $42.329 .350,00$ & $273.520 .250,00$ & $54.683 .100,00$ \\
\hline PAR & 1.818.718.523,76 & $1.130 .868 .398,19$ & $1.525 .819 .901,00$ & $194.662 .825,41$ \\
\hline MANUTENÇÃO DA ED INFANTIL & $250.686 .908,04$ & $52.097 .558,65$ & $38.998 .364,81$ & $165.644 .640,68$ \\
\hline ATENDIMENTO AO EJA & $24.990 .893,05$ & $18.333 .868,47$ & $54.679 .122,41$ & $63.313 .800,55$ \\
\hline ENSINO MÉDIO & $288.285 .988,70$ & $113.089 .210,45$ & $57.085 .420,03$ & $938.609 .045,00$ \\
\hline TOTAL & 8.296.718.415,84 & 3.518.304.993,04 & $5.377 .539 .144,36$ & $3.419 .198 .196,35$ \\
\hline
\end{tabular}

Os dados da tabela demonstram que o montante de recursos transferidos para os governos subnacionais, a título de assistência financeira voluntária para a oferta da educação básica, diminuiu drasticamente desde 2014. Considerando os anos de 2016 e 2017, houve o decréscimo de $50,5 \%$ e, considerando o valor transferido no ano de 2014 e o valor transferido em 2017, observa-se uma queda de $58,8 \%$.

Analisando mais detalhadamente os dados da Tabela 1, pode-se observar que os programas / ações que receberam menor atenção do governo Temer foram o Programa Brasil Alfabetizado, o Projovem, o Programa Brasil Carinhoso, o Programa de Construção de quadras poliesportivas e as ações de água, esgotamento sanitário e acessibilidade para escolas do campo. No caso do Projovem, observa-se uma diminuição dos recursos de $69 \%$ do ano de 2015 para o ano de 2016 e de $83 \%$ desse ano para 2017. Esses dados deixam evidente que ações com focos em grupos minoritários ou com foco em políticas de inclusão não são prioridades do governo atual.

Por outro lado, os dados evidenciam que as transferências para o ensino médio (vinculadas à implementação da reforma) foram a grande prioridade do governo no ano de 2017, que teve um aumento de $94 \%$ em relação ao ano de 2016 . Além das transferências para o ensino médio, apenas a manutenção de turmas de educação infantil e de EJA tiveram aumento, porém em uma escala bem inferior. Esse aumento ocorreu porque esses dois programas estão vinculados a novas matrículas, não sendo, portanto, uma iniciativa do governo federal. 
Além desses aspectos que os dados da Tabela 1 possibilitam observar, cabe registrar que, do total de recursos transferidos para os estados por meio do PRONATEC, R\$569,2 milhões foram destinados para o Sistema S. Esse dado demonstra que uma outra característica da assistência financeira voluntária da União a partir de 2016 foi a transferências de recursos articulada ao setor privado.

Outra característica da política de assistência técnica e financeira da União, no período em análise, foi sua associação às emendas parlamentares. Conforme apresentado no Relatório de Gestão de 2017 do FNDE, uma parte significativa do total de recursos transferidos para construção, reforma e ampliação de escolas (que se inserem em diversos programas) que, no ano de 2017 , totalizaram $\mathrm{R} \$ 205,44$ milhões, foi transferida por meio de emendas parlamentares, num montante de $\mathrm{R} \$ 125,62$ milhões.

No ano de 2017, o MEC elaborou a cartilha Orientação para apresentação de emendas parlamentares ao orçamento de 2017, destinada aos parlamentares com o objetivo de orientálos na apresentação de emendas parlamentares orçamentárias à educação. O documento apresenta informações sobre as políticas do Ministério da Educação (MEC), às quais os parlamentares podem vincular suas emendas, conforme evidenciado na apresentação do referido documento:

Nesse sentido, levando em conta o imperativo constitucional dos parlamentares de orientar a alocação de recursos públicos destinados ao desenvolvimento, à ampliação e consolidação de estratégias de fortalecimento de ações voltadas para as políticas educacionais, apresentamos à Vossa Excelência um conjunto de ações sob a responsabilidade deste Ministério para as quais a colaboração de Vossa Excelência é de grande relevância (BRASIL, 2017b, p. 7).

As ações indicadas pelo MEC englobam a educação básica, a educação profissional e tecnológica e a educação superior. Na educação básica, a cartilha apresenta um conjunto de programas da política de assistência voluntária da União aos estados e municípios, compreendendo majoritariamente ações focadas na infraestrutura escolar.

A transferência de recursos financeiros para a educação por meio de emendas parlamentares já é uma prática antiga no orçamento público da educação, porém, essa forma de transferência aumentou significativamente no ano de 2016. No período de 1998 a 2006, registra-se um total de 98 emendas orçamentárias parlamentares para a educação, equivalentes ao valor de $\mathrm{R} \$ 17.252 .547,06$. A partir de 2007, observa-se um aumento considerável das emendas orçamentárias parlamentares para a função educação, totalizando 1.805 emendas no período de 2007 a 2017, com um montante de recursos na ordem de R\$ 810.696.908,88. Do total dessas emendas, 425 foram concentradas nos anos de 2016 e 2017, correspondendo a $\mathrm{R} \$ 387.094 .424,56$. Ressalta-se que os anos de 2016 e 2017 foram marcados por grande barganha política entre legislativo e executivo, tendo em vista as pautas de denúncias ao ex-Presidente Michel Temer e os acordos para votação das reformas trabalhista e da Previdência. Assim, observa-se que as ações de assistência voluntária da União integraram o jogo de barganhas político-partidárias entre o executivo e legislativo, protagonizado entre 2016 e 2017. 
Configurações da Política de Assistência da União para a Oferta da Educação Básica Pós-Golpe de 2016

\section{Conclusões}

Os dados apresentados, ainda que incipientes, apontam que a política de assistência técnica e financeira da União, a partir de 2016, tem assumido três características principais: a) o uso dos recursos para induzir os estados a implementar a reforma do ensino médio; b) compartilhamento dos recursos de determinado programa com o setor privado; c) uso dos recursos como instrumento de barganhas político-partidárias entre executivo e legislativo.

Os dados também deixam evidente que a assistência técnica e financeira da União aos entes federados subnacionais foi amplamente afetada pela EC 95/2016, pois sendo as ações de transferências voluntárias aquelas sob as quais o governo federal possui discricionariedade, são nessas ações que o corte de gastos e as mudanças na forma de operacionalizar as transferências se fazem mais presentes. Nesse processo, os municípios são o ente mais atingido, uma vez que são os mais dependentes da assistência da União para o desenvolvimento de sua função de ofertar a educação Infantil e o ensino fundamental.

Tal questão se torna mais preocupante, quando constatamos, a partir de dados da Pesquisa Nacional por Amostra de Domicílios (PNAD) de 2015, que, apesar do discurso de universalização, ainda existem no Brasil 4,9 milhões de pessoas em idade escolar fora da escola. Desse total, 2,4 milhões são jovens, cuja entrada na escola depende amplamente das políticas de inclusão, aquelas que foram colocadas em segundo plano pelo atual governo.

\section{Referências}

ARRETCHE, Marta. Democracia, federalismo e centralização. Rio de Janeiro: Editora FGV; Editora Fiocruz, 2012.

BANCO MUNDIAL. Um ajuste justo: análise da eficiência e equidade do gasto público no Brasil. 2017.

BIANCHI, Álvaro. O que é um golpe de estado? Blog Junho, 2016. Disponível em: <http://blogjunho.com.br/o-que-e-um-golpe-de-estado>. Acesso em: 19 maio 2014.

BRASIL. Constituição da República Federativa de 1988. Diário Oficial da União, Brasília, DF, 1988. Disponível em: <http://www.planalto.gov.br/ccivil_03/Constituicao/Cons tituicao.htm>. Acesso em: 05 abr. 2012.

BRASIL. Lei no 9.394/96 de 20 de dezembro de 1996. Estabelece as Diretrizes e Bases da Educação Nacional. Diário Oficial da União, Brasília, DF, 20 dez. 1996. Disponível em: <http://www.planalto.gov.br/ccivil_03/ leis/l9394.htm>. Acesso em: 05 mai. 2013.

BRASIL. Resolução/CD/FNDE n 25, de 13 de agosto de 2003. Altera a Resolução CD/FNDE $\mathrm{n}^{\circ}$ 12, o Manual de Orientações para Assistência Financeira a Programas e Projetos Educacionais aprovado pela Resolução CD/FNDE no 13 e revoga a Resolução CD/FNDE n 17/2003. Diário Oficial da União, Brasília, DF, 2003.

BRASIL. Lei $n^{\circ} 11.494$ de 20 de junho de 2007. Regulamenta o Fundo de Manutenção e Desenvolvimento da Educação Básica e de Valorização dos Profissionais da Educação FUNDEB, de que trata o art. 60 do Ato das Disposições Constitucionais Transitórias; altera a Lei $\mathrm{n}^{\circ}-10.195$, de 14 de fevereiro de 2001; revoga dispositivos das Leis $n^{\circ} 9.424$, de 24 de dezembro de 1996, 10.880, de 9 de junho de 2004, e 10.845, de 5 de março de 2004; e dá 
Configurações da Política de Assistência da União para a Oferta da Educação Básica Pós-Golpe de 2016

outras providências. Diário Oficial da União, Brasília, DF, 20 jun. 2007a. Disponível em: <http://www.planalto.gov.br/ccivil_03/_ato2007-2010/2007/lei//11494.htm>. Acesso em: 19 maio 2014.

BRASIL. Plano de desenvolvimento em Educação: razões, princípios e programas. Brasília: Ministério da Educação, 2007b.

BRASIL. EMENDA CONSTITUCIONAL № 95, DE 15 DE DEZEMBRO DE 2016. Altera o Ato das Disposições Constitucionais Transitórias, para instituir o Novo Regime Fiscal, e dá outras providências. Diário Oficial da União, Brasília, 2016. Disponível em: <http://www.planalto. gov.br/ccivil_03/constituicao/Emendas/Emc/emc95.htm>. Acesso em: 02 jun. 2018.

BRASIL. Lei n 13.415, de 16 de fevereiro de 2017. Altera as Leis $n^{\circ} 9.394$, de 20 de dezembro de 1996, que estabelece as diretrizes e bases da educação nacional, e 11.494, de 20 de junho 2007, que regulamenta o Fundo de Manutenção e Desenvolvimento da Educação Básica e de Valorização dos Profissionais da Educação, a Consolidação das Leis do Trabalho - CLT [...]. Diário Oficial da União, Brasília, 2017a. Disponível em: <http://www. planalto.gov.br/ccivil_03/_Ato2015-2018/2017/Lei/L13415.htm>. Acesso em: 02 jun. 2018.

BRASIL. Orientação para apresentação de emendas parlamentares ao orçamento de 2017. Brasília: Ministério da Educação, 2017b.

MARIANO, Cynara Monteiro. Emenda Constitucional 95/2016 e o teto dos gastos públicos: volta ao estado de exceção econômico e ao capitalismo do desastre. Revista de Investigações Constitucionais, Curitiba, v. 4, n. 1, p. 259-281, jan./abr. 2017. Disponível em: <https://revistas.ufpr.br/rinc/article/view/50289>. Acesso em: 19 maio 2014.

OATES, Wallace E. The theory of public finance in a federal system. The Canadian Journal of Economics, Cambridge, v. 1, n. 1, p. 37-54, Feb.1968.

TSEBELIS, George. Processo decisório em sistemas políticos: veto players no presidencialismo, parlamentarismo, multicameralismo e pluripartidarismo. Revista Brasileira de Ciências Sociais, São Paulo, v. 12, n. 34, p. 89-117, jun. 1995.

WATTS, Ronald. Comparing federal systems. Montreal: McGill-Queen's University Press, 2008.

Cacilda Rodrigues Cavalcanti é doutora em Educação pela Universidade Federal de Minas Gerais (UFMG), professora do Departamento de Educação II da Universidade Federal do Maranhão (UFMA), com atuação profissional e acadêmica no campo de políticas públicas de educação, em especial, no campo da gestão e do financiamento da educação básica.

ORCID: http://orcid.org/0000-0001-7222-8061

E-mail: cavalcanticacilda@gmail.com

Recebido em 04 de fevereiro de 2019

Aprovado em 18 de abril de 2019 


\section{Editores do volume 9}

José Marcelino de Rezende Pinto - Universidade de São Paulo, São Paulo/SP, Brasil

Nalú Farenzena - Universidade Federal do Rio Grande do Sul, Porto Alegre/RS, Brasil

\section{Comitê Editorial}

José Marcelino de Rezende Pinto - Universidade de São Paulo, Brasil

Juca Gil - Universidade Federal do Rio Grande do Sul, Brasil

Theresa Adrião - Universidade Estadual de Campinas, Brasil Ângelo

Ricardo de Souza - Universidade Federal do Paraná, Brasil

Márcia Aparecida Jacomini - Universidade Federal de São Paulo, Brasil

\section{Conselho Editorial}

\section{Alejandro Morduchowicz}

Universidad Pedagógica, Provincia de Buenos Aires, Argentina

Fernanda Saforcada

Universidade de Buenos Aires, Argentina

Jacques Velloso

Universidade de Brasília, Brasil

João Monlevade

Senado Federal, Brasil

Jorge Abrahão de Castro

Instituto de Pesquisa Econômica Aplicada / IPEA, Brasil

Juca Gil

Universidade Federal do Rio Grande do Sul, Brasil

Lisete Regina Gomes Arelaro

Universidade de São Paulo, Brasil

Luis Carlos Sales

Universidade Federal do Piauí, Brasil

Luiz de Sousa Junior

Universidade Federal da Paraíba, Brasil

Luiz Fernandes Dourado

Universidade Federal de Goiás, Brasil

Magna França

Universidade Federal do Rio Grande do Norte, Brasil

\section{Maria Beatriz Luce}

Universidade Federal do Pampa, Brasil

Universidade Federal do Rio Grande do Sul, Brasil

Marcos Edgar Bassi

Universidade Federal de Santa Catarina, Brasil

\author{
Maria Dilnéia Espíndola Fernandes \\ Universidade Federal de Mato Grosso do Sul, Brasil \\ Nalú Farenzena \\ Universidade Federal do Rio Grande do Sul, Brasil \\ Nelson Cardoso do Amaral \\ Universidade Federal de Goiás, Brasil \\ Nicholas Davies \\ Universidade Federal Fluminense, Brasil \\ Rosana Evangelista Cruz \\ Universidade Federal do Piauí, Brasil \\ Rosana Gemaque \\ Universidade Federal do Pará, Brasil \\ Robert E. Verhine \\ Universidade Federal da Bahia, Brasil \\ Romualdo Portela de Oliveira \\ Universidade de São Paulo, Brasil \\ Theresa Adrião \\ Universidade Estadual de Campinas, Brasil \\ Tristan McCowan \\ University of London, Reino Unido \\ Vera Jacob \\ Universidade Federal do Pará, Brasil \\ Vera Peroni \\ Universidade Federal do Rio Grande do Sul, Brasil \\ Vitor Henrique Paro \\ Universidade de São Paulo, Brasil
}

\section{Equipe editorial}

Apoio ao Comitê Editorial: Patrícia Balthazar Garcia

Diagramação, Revisão de português e normalização: Edson Leonel de Oliveira

Revisão de inglês: Ananyr Porto Fajardo 